\title{
PIK3R5 Gene Mutation
}

National Cancer Institute

\section{Source}

National Cancer Institute. PIK3R5 Gene Mutation. NCI Thesaurus. Code C146728.

A change in the nucleotide sequence of the PIK3R5 gene. 